\title{
Cardiovascular disease in women: are we aware?
}

\section{DOENÇA CARDIOVASCULAR EM MULHERES: ISSO LHE IMPORTA?}

\author{
lucas Colombo Godor ${ }^{1 *}$, Isabela Cristina Kirnew Abud ${ }^{1}$, Carlos V. Serrano JR. ${ }^{2}$ \\ (F) S \\ ${ }^{2}$ Associate Professor of Cardiology, InCor, FMUSP. Director of the Atherosclerosis Clinical Unit at the InCor, FMUSP, São Paulo, SP, Brazil \\ Article received: $2 / 2 / 2017$ \\ Accepted for publication: $2 / 23 / 2017$ \\ *Correspondence: \\ Incor, HCFMUSP \\ Address: Av. Dr. Enéas de Carvalho Aguiar, 44, São Paulo, SP - Brazil \\ Postal code: 05403-900 \\ lucascgodoy@uol.com.br
}

Cardiovascular disease (CVD) is traditionally more related to male patients, both in medical literature and popular imaginary. It may cause some estrangement to hear that those ideas are not actually supported by epidemiological data anymore. In the United States, since the 1980s, the annual CVD mortality rate has remained higher for women than for men and so has the prevalence of CVDs. ${ }^{1}$ In Brazil, from 1980 to 2012, there was a significant reduction in cardiovascular mortality among men - particularly for ischemic heart disease mortality -, but no improvement was seen among women. ${ }^{2}$ Actress Carrie Fisher's recent sudden death during a flight, at the age of sixty, due to cardiovascular reasons, and the death of her own mother, the famous Singing in the Rain actress Debbie Reynolds, on the very next day due to a hemorrhagic stroke are events that shed light once more on women's health issues and concerns.

As doctors, we must be aware of the main differences between genders regarding CVD epidemiology and clinical presentation. Although, for the vast majority of conditions, no difference is settled in treatment guidelines for women patients, we still observe that, for example, women suffering an acute myocardium infarction often receive less intensive medical therapy, and are also less likely to undergo cardiac catheterization and less likely to receive timely reperfusion. Apparently, that translates into a worse prognosis for them compared to men. ${ }^{3-6}$

Considering ischemic heart disease, other differences exist between genders. In both acute and chronic presentations, women more frequently present the so-called "atypical" symptoms. This means that, instead of having chest pain or discomfort as their leading symptoms, women may have ischemic disease in the presence only of shortness of breath, pain in other body locations (such as arms, back, epigastrium, jaw) or nausea and vomiting, dizziness, diaphoresis, fatigue, among other uncharacteristic complaints. ${ }^{7,8}$ The workup in a given outpatient women with suspected chronic ischemic heart disease may sometimes differ to that usually done in men. Exercise electrocardiogram is more likely to show a false-positive result in women. ${ }^{9}$ Also, up to $60 \%$ of female patients with demonstrated myocardial ischemia in a non-invasive test have no obstructive coronary disease in the angiogram, suggesting that microvascular angina may be the real cause of symptoms in many women. ${ }^{10}$

When it comes to heart failure, notable differences also exist between men and women. Regarding etiology, peripartum cardiomyopathy and breast cancer chemotherapeutic toxicity are unique to the female gender. Women also present heart failure with a preserved ejection fraction more frequently than the whole population, which may account for a similar death rate in the two sexes despite lower rates of optimal guideline-directed treatment in women, especially considering the use of implantable devices (such as implantable cardioverted-defibrillator, ICD). A very peculiar form of acute myocardial dysfunction that is far more commonly seen in women is the "takotsubo cardiomyopathy" or "broken heart syndrome." The acute presentation of this disease mimics myocardium infarction, with chest pain being the chief concern and elevation of the ST segment of the electrocardiography (ECG) being the rule. Coronary angiography, unexpectedly, shows no obstructions, but ventriculography reveals an entirely abnormal contraction pattern in the left ventricle. The precise mechanism responsible for this syndrome, which usually develops 
after intense emotional stress, is still unknown. Women represent more than $90 \%$ of all patients diagnosed with takotsubo cardiomyopathy nowadays. ${ }^{11}$

CVD disease prevention is a challenge in the whole population and having a better understanding of the predispositions may help doctors and patients to prevent CVD progression. The traditional risk factors (e.g. hypertension, family history, diabetes, dyslipidemia) are similar between genders. Age is a critical issue, since postmenopausal women do carry a higher risk of developing CVD compared with other females in their reproductive years. Regarding HDL-cholesterol, women usually present higher HDL-c levels than those seen in men, but women who happen to have low HDL-c have a more than seven times increased risk of coronary events than the risk observed in men in the same situation.

The recommended non-pharmacological strategies (performing physical exercises, having a balanced and varied diet) and the pharmacological approaches, such as statin and aspirin prescription for primary and secondary prevention, are also fairly the same for both men and women. Use of hormonal contraceptives by patients with known cardiac disease, uncontrolled hypertension, smoking, and obesity may pose an excessively high risk of developing acute cardiovascular events and must be discouraged. Also, hormone replacement therapy, once thought to have protector effects on CVD, must not be recommended for indications other than treatment of menopausal symptoms. The first beneficial properties demonstrated in the early massive observational studies, such as the "Nurses' Health Study," were not confirmed in the following experimental trials (HERS and "Women's Health Initiative" being the most important ones).

Women are still underrepresented in most cardiovascular studies and, because of that, drawing conclusions of specific risk factors and treatment benefits in this population is not an easy task. Being aware that women may also be at significant risk for CVD disease may help start changing the current situation we face. Interplanetary princesses or uniquely talented artists who sing, dance and play under the pouring rain are not the only ones that deserve to be diagnosed with CVD and receive, without preventable delays, the best possible medical therapy directed towards it. Women from all ethnic, social, economic and cultural backgrounds also deserve the same standard of care. How about you, dear colleague: are you aware? So, "Good morning, good morning," "May the force be with you!"

\section{References}

1. Mozaffarian D, Benjamin EJ, Go AS, Arnett DK, Blaha MJ, Cushman M, et al.; American Heart Association Statistics Committee and Stroke Statistics Subcommittee. Heart disease and stroke statistics-2015 update: a report from the American Heart Association. Circulation 2015; 131(4):e29-322.

2. Mansur AP, Favarato D. Trends in mortality rate from cardiovascular disease in Brazil, 1980-2012. Arq Bras Cardiol. 2016; 107(1):20-5.

3. Blomkalns AL, Chen AY, Hochman JS, Peterson ED, Trynosky K, Diercks DB, et al.; CRUSADE Investigators. Gender disparities in the diagnosis and treatment of non-ST-segment elevation acute coronary syndromes: large scale observations from the CRUSADE (Can Rapid Risk Stratification of Unstable Angina Patients Suppress Adverse Outcomes With Early Implementation of the American College of Cardiology/American Heart Association Guidelines) National Quality Improvement Initiative. J Am Coll Cardiol. 2005; 45(6):832-7.

4. Radovanovic D, Erne P, Urban P, Bertel O, Rickli H, Gaspoz JM; AMIS Plus Investigators. Gender differences in management and outcomes in patients with acute coronary syndromes: results on 20,290 patients from the AMIS Plus Registry. Heart. 2007; 93(11):1369-75.

5. Jneid H, Fonarow GC, Cannon CP, Hernandez AF, Palacios IF, Maree AO, et al.; Get With the Guidelines Steering Committee and Investigators. Sex differences in medical care and early death after acute myocardial infarction. Circulation. 2008; 118(25):2803-10.

6. Otten AM, Maas AH, Ottervanger JP, Kloosterman A, van 't Hof AW, Dambrink $\mathrm{JH}$, et al.; Zwolle Myocardial Infarction Study Group. Is the difference in outcome between men and women treated by primary percutaneous coronary intervention age dependent? Gender difference in STEMI stratified on age. Eur Heart J Acute Cardiovasc Care. 2013; 2(4):334-41.

7. Canto JG, Goldberg RJ, Hand MM, Bonow RO, Sopko G, Pepine CJ, et al. Symptom presentation of women with acute coronary syndromes: myth vs reality. Arch Intern Med. 2007; 167(22):2405-13.

8. Bairey Merz CN, Shaw LJ, Reis SE, Bittner V, Kelsey SF, Olson M, et al.; WISE Investigators. Insights from the NHLBI-sponsored Women's Ischemia Syndrome Evaluation (WISE) study: Part II: gender differences in presentation, diagnosis, and outcome with regard to gender-based pathophysiology of atherosclerosis and macrovascular and microvascular coronary disease. J Am Coll Cardiol. 2006; 47(3 Suppl):S21-9.

9. Reynolds HR, Srichai MB, Iqbal SN, Slater JN, Mancini GB, Feit F, et al Mechanisms of myocardial infarction in women without angiographically obstructive coronary artery disease. Circulation. 2011; 124(13):1414-25.

10. Sharaf BL, Pepine CJ, Kerensky RA, Reis SE, Reichek N, Rogers WJ, et al.; WISE Study Group. Detailed angiographic analysis of women with suspected ischemic chest pain (pilot phase data from the NHLBI-sponsored Women's Ischemia Syndrome Evaluation [WISE] study angiographic core laboratory) Am J Cardiol. 2001; 87(8):937-41.

11. Tsuchihashi K, Ueshima K, Uchida T, Oh-mura N, Kimura K, Owa M, et al.; Angina Pectoris-Myocardial Infarction Investigations in Japan. Transient left ventricular apical ballooning without coronary artery stenosis: a novel heart syndrome mimicking acute myocardial infarction. Angina PectorisMyocardial Infarction Investigations in Japan. J Am Coll Cardiol. 2001; 38(1):11-8. 